\title{
Orçamento e planejamento municipal: um estudo de caso
}

\author{
Municipal budget and planning: a case study
}

ELOI DALLA VECCHIA*

MARCO ANTONIO MONTOYA**

\begin{abstract}
RESUMO: O presente artigo busca avaliar a eficiência do planejamento na área municipal, no período de 1989 a 1997, com o objetivo de estabelecer se a variável inflação determina níveis mais altos ou mais baixos considerando o ajuste municipal. Para isso, foi utilizado como banco de dados o orçamento de 67 municípios da região do Platô Médio do estado do Rio Grande do Sul. O processo metodológico implicou a construção de índices eficientes, avaliados por meio da nota de ajuste da variável orçamento. Verificou-se que: a) a variável inflação não é a única determinante do ajuste do planejamento municipal; b) Existe, na equipe técnica municipal, falta e deficiência em relação ao planejamento e ao orçamento (técnico) da disciplina; c) A ausência de um processo formal e estabelecido que possa avaliar as propostas orçamentárias, na discussão e aprovação das leis, considerando esta uma responsabilidade legislativa. Conclui-se, portanto, que os legisladores, principalmente no período de fixação de preços, não foram eficientes, considerando o exercício de suas funções, julgamento, discussão e aprovação das leis orçamentárias nas cidades da Região do Platô Médio do estado do Rio Grande do Sul. Sul, pois permitiram o orçamento sistemático de superavaliação, que propunha a geração de uma série de déficits.

PALAVRAS-CHAVE: orçamento; planejamento; governo municipal.
\end{abstract}

ABSTRACT: The present article searches to evaluate the efficiency of planning in the municipal area, within the period of 1989 to 1997, aiming to establish if the variable inflation determines higher or lower levels considering the municipal adjusting. For this, it was used as data base the budget of 67 municipal districts of the Medium Plateau region of the state of Rio Grande do Sul. The methodological process implied the construction of efficient indexes, evaluated through the adjust grade of the budget variable. It was verified that: a) the variable inflation is not the only determining of the municipal planning adjusting; b) It exists,

\footnotetext{
* Professor da Faculdade de Economia e Administração da Universidade de Passo Fundo - UPF, Passo Fundo/RS, Brasil. E-mail: Eloi.vecchia@epf.br.

* Professor Titular da Faculdade de Economia e Administração da Universidade de Passo Fundo (UPF). E-mail: montoya@upf.tche.br; Orcid: 0000-0003-1566-7417.
} 
in the municipal technical staff, lack and deficiency about the planning and the discipline (technical) budget; c) The absence of a formal and established process that could evaluate the budget proposals, in the discussion and approval of the laws, considering this a legislative responsibility. Therefore, it concludes that the legislators, mainly in the period of price establishment, were not efficient considering the exercise of their jobs, judgment, discussion and approval of the budget laws in the cities of the Medium Plateau Region of the state of Rio Grande do Sul, since they permitted the systematic superevaluation budget, which proposed the generation of a series of deficits.

KEYWORDS: budget; planning; municipal government.

JEL Classification: H7; R51.

\section{INTRODUÇÃO}

A economia brasileira vivenciou nas últimas décadas, até 1994, um processoinflacionário bastante acentuado, deixando arraigada a chamada cultura inflacionária, tanto nas pessoas como nas própria instituições, públicas e privadas. Em razão desse fato, a prática orçamentária, de certa forma, foi perdendo, para a grande maioria dos gestores do orçamento público, o seu verdadeiro sentido de ser um instrumento eficaz de planejamento e controle. De fato, para muitos, o orçamento passou a ser considerado uma atividade de "futurologia", visto que se tornava extremamente difícil fazer previsões de receitas e estabelecer montantes de despesas para a área pública para um período futuro, ao qual se referem os orçamentos públicos. Esse problema era vivido por qualquer esfera de governo, tanto federal como estadual e municipal.

A partir de julho de 1994, nossa economia passou a experimentar uma situação de estabilidade média de preços, o que ocasionou baixos níveis dos índices inflacionários, pelo menos se comparados àqueles que a economia vinha experimentando. O fato é perfeitamente comprovado pelos índices oficialmente divulgados: os níveis do Índice Geral de Preços — Disponibilidade Interna — IGP-DI, publicado pela revista Conjuntura Econômica, de dezembro de 1997, atingiram 1.037,60\% no ano de $1988,1.782,90 \%$ no ano seguinte, 1989 e $1.699,70 \%$ em 1990; o Índice Geral de Preços - IGP-M - FGV, em 1991, foi de 458,37\%, passando para $1.174,47 \%$ em 1992 e $2.567,46 \%$ em 1993 . Este período, no presente trabalho, foi caracterizado como Período Inflacionário.

Com o advento do Plano Real, houve uma drástica redução desses índices, que chegaram a 15,25\% em 1995; 9,20\% em 1996, atingindo, em 1997, 7,74\%, que definimos, para fins deste estudo, como Período de Estabilização. Claro está, portanto, que o Plano Real estabeleceu uma nova realidade com relação aos índices inflacionários dos últimos anos, fato que deveria causar uma influência direta sobre a técnica orçamentária desenvolvida pelos órgãos públicos. Com base nisso e em razão de o orçamento público ser definido como um instrumento de planejamento, procurou-se investigar o grau de eficiência da atividade de planejamento existente na esfera municipal, através das elaborações e execuções dos orçamentos. Assim, 
questiona-se: em que medida um contexto de estabilização inflacionária pode significar um planejamento mais eficiente e eficaz em relação à técnica orçamentária praticada nos municípios? Portanto, o artigo tem como objetivo principal: verificar se a estabilização econômica contribuiu para uma melhor eficiência nas técnicas de planejamento e orçamento na área municipal.

Com esse fim, o artigo está organizado da seguinte maneira: na seção 2, apresenta-se o processo metodológico desenvolvido para avaliar a eficiência do planejamento, bem como os critérios de escolha do conjunto de municípios analisados; na seção 3, discutem-se os resultados que analisam índices de acerto na fixação da despesa, da receita e os padrões de eficiência que apresentam; finalmente, na última seção são apresentados as conclusões mais importantes da pesquisa.

\section{PROCESSO METODOLÓGICO}

A seguir são apresentados um conjunto de índices que foram criados e/ou desen-volvidos para avaliar especificamente a eficiência no planejamento municipal, através dos resultados de orçamentos planejados e executados.

\section{1. Índices de avaliação da eficiência do planejamento municipal}

Para a evidenciação dos fatos, ou seja, o conhecimento da realidade, o conjunto de dados que compõem as variáveis da pesquisa, após sua sistematização, foi submetido a uma análise horizontal, a qual avaliou o comportamento entre a previsão da receita e fixação da despesa e a efetiva arrecadação e despesa empenhada ou realizada, em torno de cada exercício econômico-financeiro. Também as transposições de dotações orçamentárias que se consubstanciam pelo montante de créditos adicionais foram objeto dessas análises. Em seqüência, no sentido de complementação, foi feita uma análise vertical, que permitiu a comparação da evolução histórica de 1989 a 1997, salientando o comportamento dos dois períodos, definidos como inflacionário e de estabilidade de preços.

Nesse contexto, foram utilizados os seguintes critérios para fins de análise e avaliação: a) grau de discrepância entre o montante da receita estimada e o montante da receita arrecadada; b) grau de discrepância entre o montante da despesa fixada ou autorizada e o montante da despesa empenhada, ou realizada; c) nível de utilização de créditos adicionais.

Operacionalizaram-se esses critérios e em seqüência foram construídos vários indicadores que em conjunto denominamos como Índices de Eficiência do Planejamento Municipal.

Índice de Acerto na Fixação da Despesa (IAFD)

$\mathrm{IAFD}_{\mathrm{t}}=\mathrm{DE}_{\mathrm{t}} \mathrm{DF}_{\mathrm{t}}(1)$ onde:

$D E_{t}$ representa o montante da despesa empenhada ou realizada no período $t$;

$D F_{t}$ é o montante da despesa fixada para o período $t$.

Este índice representa a eficiência no planejamento na área de estabelecimento 
das ações governamentais, plano de governo e mensuração dos custos para a implementação ou execução deste plano, que corresponde ao planejamento. Ele indicará o máximo de eficiência da função de planejar quando for igual a 1 (um). Quanto maior for a discrepância em relação a este parâmetro (um), mais ineficaz apresenta-se o planejamento nesta área. Quanto mais for a discrepância entre o montante da despesa empenhada, ou realizada, do montante fixado ou autorizado, maior será a distância entre a previsão e a realidade. Quanto mais próximo for o montante da despesa empenhada, do montante da despesa fixada, mais eficaz será o planejamento.

Índice de Acerto na Estimação da Receita (IAER)

$\mathrm{IAER}_{\mathrm{t}}=\mathrm{RR}_{\mathrm{t}} \mathrm{RE}_{\mathrm{t}}(2)$ onde:

$R R_{t}$ representa o montante da receita realizada no período $t$;

$R E_{t}$ é o montante da receita estimada para o período $t$.

Este índice mostra a eficiência no planejamento na área da receita pública e indica o máximo de eficácia quando for igual a 1 (um), pois, traduzindo, representa que as estimações estavam corretas. Quanto maior for a discrepância em torno do parâmetro 1 (um), mais ineficaz se apresentará o planejamento nesta área, já que mostra um distanciamento entre as estimações e a realidade.

Índice de Utilização de Créditos Adicionais em relação à despesa empenhada ou realizada (IUCA)

IUCAt $=$ CAt $/ \operatorname{DEt}(3)$ onde:

$C A_{t}$ representa os créditos adicionais no período $t$.

Este índice representa o quanto da despesa realizada ou empenhada foi autorizada durante a execução orçamentária, ou seja, da execução do orçamento do período t.

Índice de Utilização de Créditos Adicionais em relação à despesa fixada (IUCA1) IUCA $1_{t}=\mathrm{CA}_{\mathrm{t}} / \mathrm{DF}_{\mathrm{t}}$

Este índice representa o quanto de incremento foi dado à despesa inicialmente fixada na Lei de Meios, correspondendo ao ajustamento total necessário ao planejamento.

Esses índices indicam a eficiência no planejamento, pois tanto o IUCA como o IUCA1 mostram o quantum de créditos orçamentários foram transpostos nas diversas funções, programas, subprogramas, projetos e atividades, bem como elementos de despesa. Mostram ainda o grau de mobilidade interna do orçamento-programa. Isto é, evidenciam o grau de ajustes que se fizeram necessários durante o exercício, corrigindo o planejamento inicial, pelo menos sob o aspecto financeiro, envolvendo as previsões de custos das realizações. Porém, muitas vezes tais ajustes de créditos orçamentários representam o abandono de projetos e/ou atividades no todo ou em parte. Por outro lado, esses mesmos créditos vão se somar a dotações insuficientemente previstas para custear projetos e atividades ou, ainda, por acréscimos físicos nas unidades de serviços prestados, bens produzidos etc., além dos níveis inicialmente planejados.

Ambas situações vêm demonstrar algum grau de não-correspondência entre o planejamento e o orçamento. Significa dizer que a função governamental e admi- 
nistrativa de planejar apresentou deficiência, já que a própria lei definiu créditos adicionais como sendo "as autorizações de despesas não computadas ou insuficientemente dotadas na Lei de Orçamento".

Esse índice indica eficiência máxima, considerado esse conceito sob a ótica de atingir os objetivos e metas estabelecidos na lei orçamentária, quando for igual a zero. Quanto maior for esse índice, mais ineficaz será o planejamento. Quanto menor for a utilização de créditos adicionais durante a execução de um orçamento-programa, mais eficaz se apresentará o planejamento. Quanto maior for a utilização de créditos adicionais durante a execução de um orçamento-programa, teoricamente, menor será a eficiência do planejamento.

Finalmente, cabe salientar que na literatura não é encontrado qualquer parâmetro que auxilie na definição de qual é o nível de discrepância ou afastamento do grau de eficiência máxima aceitável para se julgar o acerto no planejamento em função da execução orçamentária, seja em relação à receita, IAER, seja em relação à execução da despesa, IAFD, bem como no que se refere aos índices dos Créditos Adicionais. Os indicadores conhecidos se referem à análise de balanços e orçamentos, não vinculando essas análises ao planejamento. Portanto, o processo de avaliação construído apresenta características inéditas para a avaliação da eficiência do planejamento municipal.

\subsection{Fonte e natureza dos dados}

A região do Planalto Médio do estado do Rio Grande do Sul foi escolhida para a pesquisa pelas seguintes características básicas: a) dos 67 municípios da região, 66 são considerados de pequeno porte e constituídos por uma população inferior a 50 mil habitantes; b) a elaboração dos orçamentos municipais está a cargo do órgão fazendário municipal, ou seja, Secretaria da Fazenda, e não de um órgão de planejamento; c) além da baixa densidade populacional, são todos municípios considerados, em relação à propriedade, de minifúndios.

Em conjunto, tais características fazem com que o orçamento esteja desvinculado, na fase de concepção e elaboração, da atividade ou função pública do planejamento, já que é o próprio contador responsável pelas demonstrações contábeis da prefeitura quem exerce, além de outras, essa atividade.

\section{A EFICIÊNCIA DO PLANEJAMENTO MUNICIPAL}

O conjunto de créditos orçamentários consignados inicialmente na lei orçamentária corresponde à fixação da despesa de cada exercício econômico-financeiro, quando a análise se referir à ótica da orçamentação. No entanto, esses créditos, durante a execução orçamentária, podem ser ajustados para mais ou para menos, dependendo das necessidades que a realidade apresentar no decorrer do tempo. Tais 
ajustes são feitos sempre com autorização de lei, autorização esta que pode fazer parte de algum dispositivo da própria lei orçamentária anual, ou por leis que são editadas durante o próprio exercício. O conjunto de créditos ajustados, segundo a interpretação da própria lei, pode ser definido como despesa autorizada. Este montante de créditos ajustados é o limite de realizações financeiras que a administração pública municipal ou de qualquer outra esfera de governo está obrigada a obedecer. O montante de realizações dos créditos autorizados vai corresponder à despesa empenhada.

Duas definições de despesas orçamentárias estão presentes: a despesa fixada, aquele montante que a lei de orçamento estabeleceu, quando de sua aprovação, para um exercício financeiro - que, no Brasil, corresponde ao ano civil, por força do dispositivo estabelecido no artigo 34 da lei federal 4.320/64 -, e a despesa autorizada, que corresponde às autorizações iniciais, acrescidas do montante de créditos adicionais autorizados e abertos durante a própria execução orçamentária, ou seja, os ajustes legalmente permitidos (e efetuados) no orçamento inicial.

Como se observa, a despesa fixada e a despesa autorizada poderão até corresponder ao mesmo montante, porém isso raramente ocorre. Explicando, quer-se dizer que essa igualdade só vai acontecer nas seguintes condições: primeiro, se não ocorrer a utilização de créditos adicionais; segundo, ocorrendo a utilização de créditos adicionais, o montante total de créditos adicionais deve ter única e exclusivamente como fonte de recurso a redução de dotações orçamentárias. Ou seja, os valores acrescidos aos créditos inicialmente orçados correspondem a igual soma ou valor nas reduções de outros créditos, mantendo-se inalterado o montante global inicial.

A análise desses ajustes é feita com o auxílio dos índices de utilização de créditos adicionais, IUCA e IUCA1

\section{1. Índice de Acerto na Fixação da Despesa - IAFD, e Índice de Acerto na Estimação da Receita — IAER}

O índice que auxiliará na análise da despesa é o Índice de Acerto na Fixação da Despesa - IAFD, o qual tem origem na relação despesa empenhada e despesa fixada. Esses índices dos municípios da região, apresentados na Tabela 1 e Gráficos 1 e 2 , em termos médios, tanto para a série de exercícios como para cada um dos períodos da série, ou seja, o período denominado inflacionário e o de estabilização de preços, permitem salientar alguns padrões de comportamento.

Nos gráficos 1 e 2, a linha que corta o eixo vertical em 1 (um) representa a eficiência máxima no planejamento, avaliado sob a ótica da fixação da despesa e estimava da receita, respectivamente, conforme os parâmetros e definições expostos no capítulo da metodologia deste trabalho. 
Notam-se dois comportamentos. No período denominado de inflacionário, o IAFD, que aqui está representado pela média anual, ficou sempre acima do parâmetro 1 (um), apresentando-se em 1,11 no exercício de 1991 e em 4,81 no exercício de 1990. Interpretando esses dados, pode-se dizer que, no exercício de 1991, a média de despesa empenhada nos 67 municípios foi de $11 \%$ acima da fixada. Já no exercício de 1990 , essa média de empenhos correspondeu a $381 \%$ acima da base orçamentária, ou seja, do montante fixado para esse mesmo exercício.

Nesse período, 1989 a 1993, a média desse índice ficou em 3,02, Tabela 1, o que indica uma média de despesa empenhada de $202 \%$ acima da média da fixação estabelecida pelos orçamentos. Nos cinco anos que compõem o período, o exercício de 1991 se apresenta bastante atípico motivo pelo qual se excluem os dados a ele referentes da série, verificando-se nos restantes que a média do Índice de Acerto na Fixação da Despesa passou para 3,50, indicando que, em média, nos anos de 1989, 1990, 1992 e 1993, as despesas orçamentárias superaram em 250\% as estabelecidas pelos orçamentos iniciais (Tabela 1 ).

A análise de índices pode também ser feita sob o enfoque da receita, com o que se obtém o Índice de Acerto na Estimação da Receita — IAER, que permite a realização de diversas análises, voltadas para as fontes de financiamentos dos programas de governo, ou para a implementação do planejamento efetuado (Tabela $1 \mathrm{e}$ Gráfico 2).

Nesse sentido, o IAER, proveniente da relação Receita Arrecadada e Receita Prevista, ou seja, da divisão do montante da arrecadação efetivamente ocorrida no exercício pelo montante que havia sido previsto quando da elaboração do orçamento para esse mesmo exercício, tem apresentado diferentes comportamentos em relação aos dados levantados nos dois períodos, o inflacionário e o de estabilização de preços (Tabela 1 e Gráfico 2).

No período denominado de inflacionário, o IAER, representado pela média

Tabela 1: Índice Médio de Acerto na Fixação da Despesa - IAFD e na

Estimação da Receita - IAER - 89/93 e 95/97

\begin{tabular}{ccccc}
\hline Anos & $\begin{array}{c}\text { Índice de acerto } \\
\text { na fixação } \\
\text { da despesa }\end{array}$ & $\begin{array}{c}\text { Média de períodos } \\
\text { em análise }- \\
89 / 93 \text { e 95/97 }\end{array}$ & $\begin{array}{c}\text { Índice de acerto } \\
\text { na estimação } \\
\text { da receita }\end{array}$ & $\begin{array}{c}\text { Média de períodos } \\
\text { em análise - } \\
89 / 93 \text { e 95/97 }\end{array}$ \\
\hline 1989 & 3,36 & & 3,75 & - \\
1990 & 4,81 & 4,96 & - \\
1991 & 1,11 & 1,15 & - \\
1992 & 2,84 & 3,02 & 2,77 & - \\
1993 & 2,97 & & 3,22 & 3,17 \\
\hline 1995 & 0,69 & & 0,66 & - \\
1996 & 0,88 & 0,80 & - \\
1997 & 0,82 & 0,80 & 0,83 & 0,76 \\
\hline
\end{tabular}

Fonte: Dados da pesquisa, elaborados com base nos balanços municipais disponíveis no TCE. 
Gráfico 1: Índice Médio de Acerto na Fixação da Despesa - IAFD

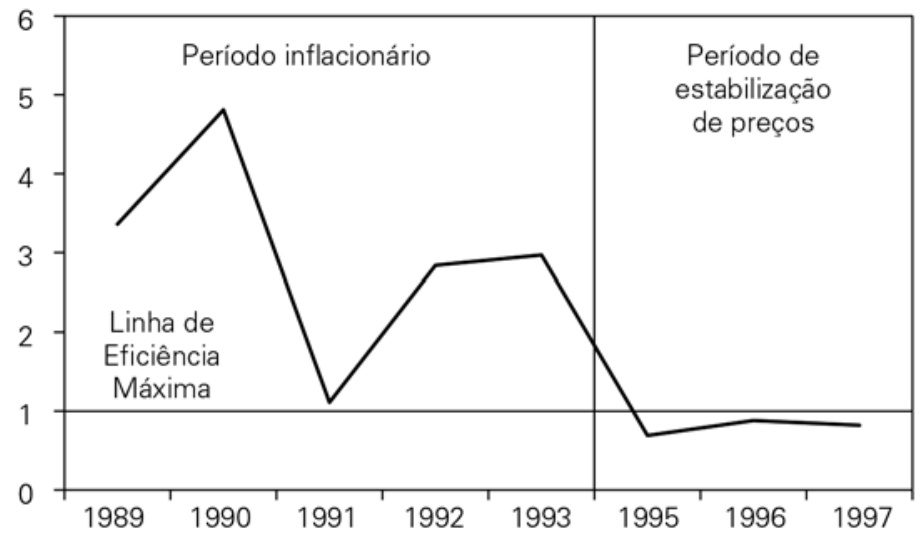

Fonte: Tabela 1.

Gráfico 2: Índice Médio de Acerto na Estimação da Receita - IAER

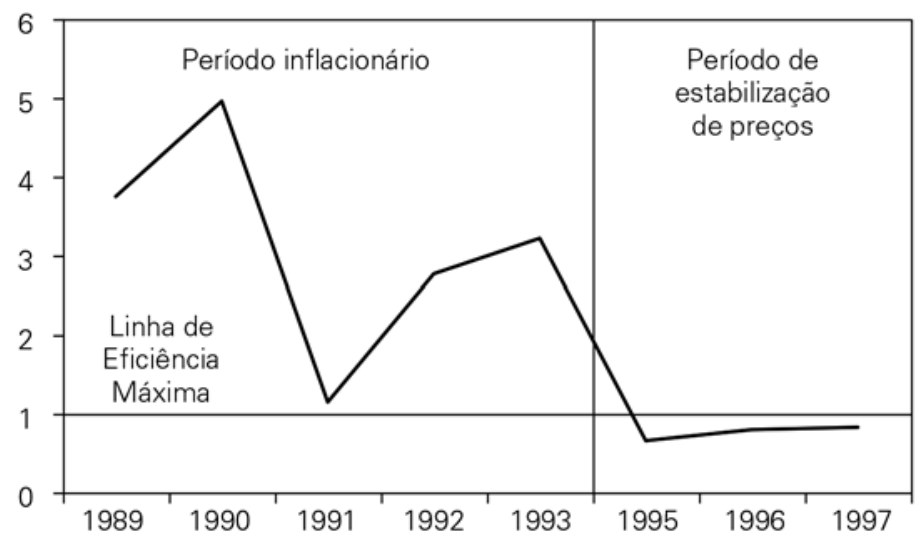

Fonte: Tabela 1

anual, ficou sempre acima do parâmetro 1 (um), apresentando-se em 1,15 no exercício de 1991, ano em que mais se aproximou do parâmetro considerado de eficiência máxima, e 4,96 no exercício de 1990, distanciando-se bastante do índice l (um). Isso equivale a dizer que a média de receita arrecadada nos 67 municípios da região ficou acima da estimativa: 15\% em 1991 e 396\% no exercício de 1990 (Tabela 1).

No período inflacionário, 1989 a 1993, a média do IAER ficou em 3,17, o que indica uma média de arrecadação de $217 \%$ acima da média da estimação das receitas orçamentárias. Em relação aos anos que compõem o período, o exercício de 1991 apresenta um comportamento muito diferente dos demais. Assim, excluindose da série os dados referentes a esse ano, verifica-se que a média do Índice de Acerto na Estimação da Receita elevou-se para 3,67, revelando, nos anos de 1989, 
1990, 1992 e 1993, que as receitas orçamentárias superaram, em média, 267\% as previsões iniciais (Tabela 1 ).

Uma rápida análise dos dados da tabela 1 e dos gráficos 1 e 2 permite concluir que houve um comportamento inverso, no período denominado de estabilização de preços, em relação ao período inflacionário. Nota-se que tanto o IAFD, como o IAER se mantiveram, nos três exercícios, 1995, 96 e 97, abaixo da linha de eficiência máxima. Esse padrão leva-nos a concluir que os orçamentos se apresentaram, nesse período, superestimados, alcançando uma média de $80 \%$ para o IAFD e de $76 \%$ para o IAER, revelando também, no confronto desses dois índices, um período caracterizado como deficitário.

\subsubsection{Padrão de eficiência no acerto da fixação da despesa e no acerto da estimação da receita}

Outra análise que os dados permitem realizar é em função do nível de discrepância em relação ao grau de eficiência máxima no planejamento.

A característica mais importante que mostra a tendência dos dados no período inflacionário indica que houve um comportamento médio de uma subavaliação orçamentária, no qual o IAER apresenta uma média de 3,17, e as discrepâncias oscilam entre 4,96 e 1,15. Já, para a Despesa Fixada, o IAFD apresenta uma média de 3,02, e as discrepâncias oscilam entre 4,81 e 1,11. Essa é uma característica constante para o período, já que a linha representativa do IAER e o IAFD, localizamse, em todo o período, acima da linha representativa do índice de eficiência máxima, ou seja, em relação a 1 (um) (Tabela 2 e Gráficos 3 e 4).

Tabela 2: Discrepância entre Índice Incorrido e Índice Representativo do Grau Máximo de Eficiência, no Período Inflacionário (1989/1993) e no Período de Estabilização de Preços (1995/1997)

\begin{tabular}{ccccccc}
\hline Anos & $\begin{array}{c}\text { Índice } \\
\text { de Acerto } \\
\text { na Fixação } \\
\text { da Despesa }\end{array}$ & $\begin{array}{c}\text { Padrão de } \\
\text { Eficiência } \\
\text { Máxima }\end{array}$ & Discrepância & $\begin{array}{c}\text { Índice } \\
\text { de Acerto } \\
\text { na Estimação } \\
\text { da Receita }\end{array}$ & $\begin{array}{c}\text { Padrão de } \\
\text { Eficiência } \\
\text { Máxima }\end{array}$ & Discrepância \\
\hline 1989 & 3,36 & 1,0 & 2,36 & 3,75 & 1,0 & 2,75 \\
1990 & 4,81 & 1,0 & 3,81 & 4,96 & 1,0 & 3,96 \\
1991 & 1,11 & 1,0 & 0,11 & 1,15 & 1,0 & 0,15 \\
1992 & 2,84 & 1,0 & 1,84 & 2,77 & 1,0 & 1,77 \\
1993 & 2,97 & 1,0 & 1,97 & 3,22 & 1,0 & 2,22 \\
Média & 3,02 & - & 2,02 & 3,17 & - & 2,17 \\
\hline 1995 & 0,69 & 1,0 & $(0,31)$ & 0,66 & 1,0 & $(0,34)$ \\
1996 & 0,88 & 1,0 & $(0,12)$ & 0,80 & 1,0 & $(0,20)$ \\
1997 & 0,82 & 1,0 & $(0,18)$ & 0,83 & 1,0 & $(0,17)$ \\
Média & 0,80 & - & $(0,20)$ & 0,76 & - & $(0,24)$ \\
\hline
\end{tabular}

Fonte: Dados da pesquisa, elaborados com base nos balanços municipais disponíveis no TCE. 
Gráfico 3: Discrepância entre Índice de

Eficiência Máxima e índices Incorridos - IAFD-1989/1993

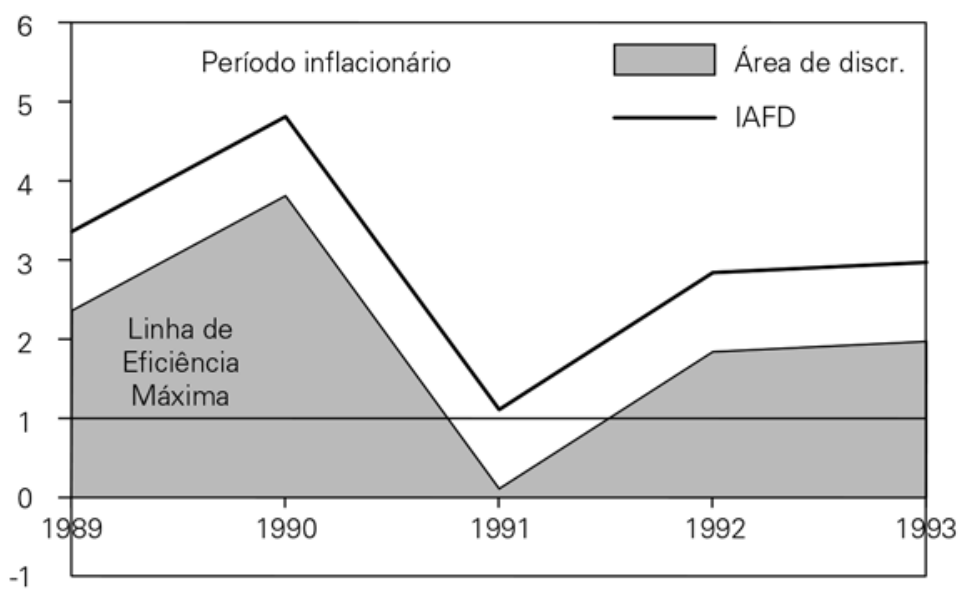

Fonte: Tabela 2

Gráfico 4: Discrepância entre Índice de Eficiência Máxima e Índices Incorridos - IAER-1989/1993

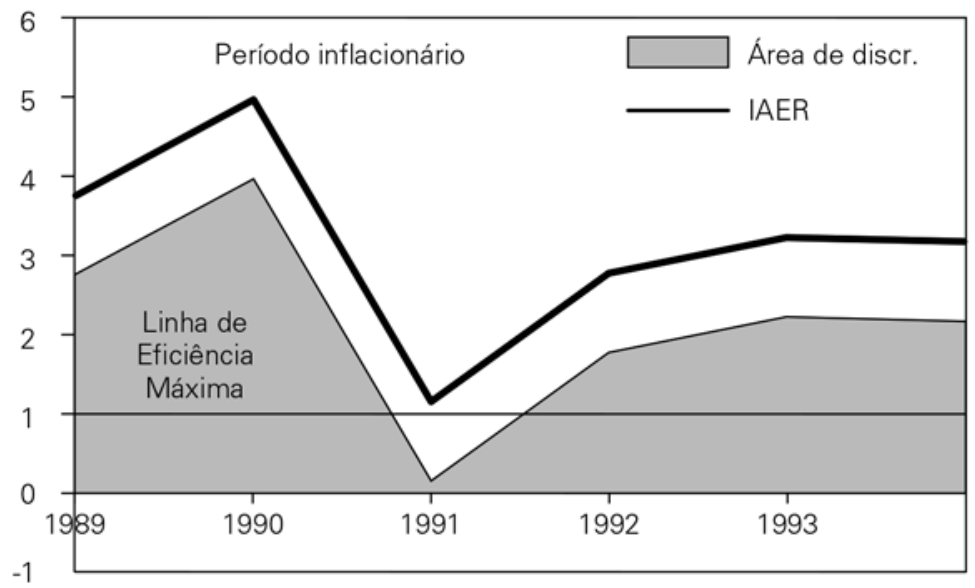

Fonte: Tabela 2

As linhas que representam as discrepâncias entre o índice incorrido e o índice representativo da eficiência máxima no período inflacionário tiveram seu comportamento em níveis elevados e sempre superior a 1, com exceção apenas do exercício de 1991, quando as discrepâncias ficaram em 0,11 para a despesa e 0,15 para a receita. O eixo que corta a linha vertical no ponto zero apresenta o nível de discrepância nulo (maior eficiência). 
Quando se observam os dados referentes ao período de estabilização de preços, Tabela 2 e Gráficos 5 e 6, de imediato, conclui-se diferentemente. Para o período de estabilização de preços, nota-se um comportamento oposto em relação aos valores dos índices, pois todos eles se estabeleceram abaixo do parâmetro 1 (um). Traduzindo, tem-se que os orçamentos, nesse período, em média, apresentaram-se superestimados em relação à real capacidade de arrecadação dos municípios da região, e, conseqüentemente, além da capacidade de realizar despesas.

O comportamento do IAER e do IAFD no período de estabilização de preços, nos três exercícios, ocorreu sempre abaixo do parâmetro 1 (um), o que revela a prática, nos municípios pesquisados, de uma projeção orçamentária além da capacidade local, já que a arrecadação da receita, assim como a execução da despesa, comportaram-se bastante aquém dos montantes estimados e fixados, respectivamente, em qualquer dos três anos. Portanto, o nível de planejamento proposto não foi alcançado.

A arrecadação dos 67 municípios nesse período apresentou um IAER médio de 0,76 , o que significa dizer que, em média, os organismos municipais arrecadaram, nos três anos, $76 \%$ de suas estimativas orçamentárias (Tabela 2).

Paralelamente, as despesas também não se realizaram nos níveis autorizados, porém superaram os níveis de realização da receita. Esses municípios, em média, atingiram, no período um IAFD de 0,80 (Tabela 2), representando compromissos assumidos com despesas de $80 \%$ das dotações orçamentárias.

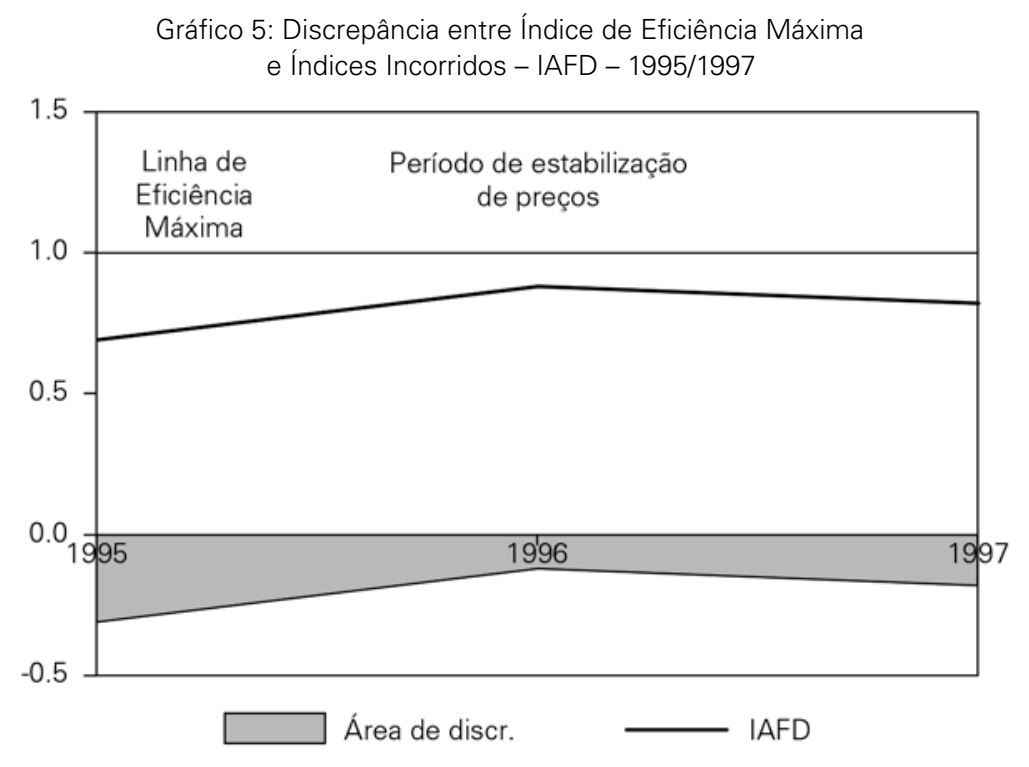

Fonte: Tabela 2 
Gráfico 6: Discrepância entre Índice de Eficiência Máxima

e Índices Incorridos - IAER - 1995/1997

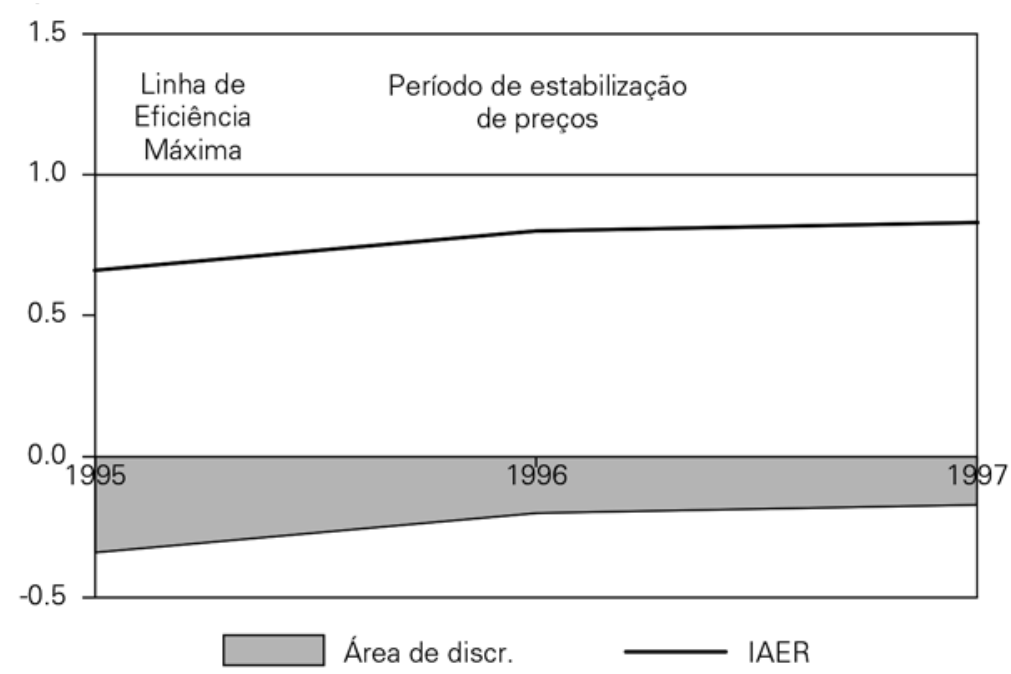

Fonte: Tabela 2

No confronto desses dados, fica revelado que, em média, houve um endividamento nos municípios pesquisados, já que o IAFD é maior que o IAER no período.

As linhas que representam as discrepâncias ocorridas entre o IAFD e o IAER no período de estabilização de preços, conforme Gráficos 5 e 6, respectivamente, revelam o quanto faltou para a realização da despesa e para a arrecadação da receita para atingir os níveis orçamentariamente propostos. Verifica-se que as linhas estão sempre abaixo da linha representativa da eficiência máxima, ou seja, a que corta o eixo vertical no ponto 1 (um), onde se tem a discrepância nula.

\subsection{Padrão de eficiência na utilização de créditos adicionais - conceituação e interpretação}

Para a abertura de créditos adicionais aos já existentes no orçamento inicial, deve haver a indicação de recurso para dar-lhes o suporte. As fontes desses recursos que a lei admite para a abertura de créditos adicionais são: superávit financeiro apurado em balanço patrimonial do exercício anterior; operações de crédito; anulação parcial ou total de dotações orçamentárias ou de créditos adicionais, autorizados em lei; e excesso de arrecadação. Assim, dependendo da fonte utilizada, isso significará mudança no total das despesas orçamentárias, como a utilização de excesso de arrecadação, utilização de superávit financeiro do exercício anterior, ou operações de créditos não computadas no montante da receita estimada, ou seja, que já fazem parte do orçamento inicial. Somente não haverá modificações no montante da despesa e, em conseqüência, no da receita, quando a fonte de recurso utilizada for a redução parcial ou total de dotações orçamentárias já consignadas. 
Como já se aventou durante as exposições, uma discrepância dos índices IAER e IAFD em relação ao parâmetro de eficiência máxima, que é 1 (um) quando os orçamentos se apresentam subavaliados, demonstra, desde logo, também a ocorrência de excesso de arrecadação e, por outro lado, um ajuste dos créditos orçamentários via a abertura de créditos adicionais, exatamente para a utilização do excedente de receita e suprimento das deficiências de dotações.

Podem, no entanto, também ocorrer, em períodos em que os orçamentos são superestimados, ajustes necessários para cobrir deficiências de dotações orçamentárias, previstas ou não previstas no orçamento inicial, correspondendo, respectivamente, aos créditos suplementares e especiais. A prática tem demonstrado que, nos orçamentos municipais, sempre ocorreram tais deficiências, em maior ou menor nível, nos dois períodos analisados; contudo, no período inflacionário, os níveis de discrepâncias se apresentaram muito mais acentuados que no de estabilização de preços.

Com o auxílio do IUCA e do IUCA1 pode-se fazer uma análise dos ajustes orçamentários que se fizeram necessários, durante a execução do próprio orçamento, já que revelam o grau de mobilidade dos créditos orçamentários e/ou o incremento de tais créditos.

Nesse contexto, a questão que se coloca é: qual é o grau de utilização de créditos adicionais que se pode considerar para se apontar deficiência no planejamento? Não existe na literatura pesquisada uma resposta a essa pergunta. $O$ fato incontestável, no entanto, é que o próprio conceito legal antes já mencionado conclui por uma deficiência. Assim, tem-se que o nível zero de utilização de créditos adicionais durante a execução anual de um orçamento público estaria revelando que foram previstos todos os elementos de despesas, com dotações suficientes para o atendimento das necessidades de serviços públicos e dos investimentos desejados, inseridos em projetos e atividades, distribuídos nos diversos órgãos da administração pública municipal, ou unidades orçamentárias.

É evidente que não se pretende que os municípios, ou qualquer outro órgão público, planejem suas atividades provendo os custos para as execuções sem qualquer margem de erro. Isso seria difícil por duas razões: uma porque o futuro pertence ao "amanhã, e o planejamento é uma atividade humana de prever ou moldar o futuro, sendo, por isso, passível de erro, por mais auxiliado que o homem esteja pela tecnologia e por conhecimento que possa adquirir; outra razão é que o planejamento não pode ser estático, sendo admissíveis a adaptação, os ajustes para a retomada dos rumos desejados, ou de posições a partir das quais antes não era possível fazer previsões.

Esses fatos justificam a utilização de créditos adicionais nos orçamentos públicos exatamente para suprir as deficiências, ou para contemplar ações não previstas inicialmente, mas que por qualquer razão são socialmente necessárias e justificáveis durante a execução de um plano.

No entanto, a boa técnica orçamentária e a observância dos princípios orçamentários, em conjunto, requerem que as informações de custos de cada unidade de serviços públicos, bens adquiridos ou produzidos etc., que compõem a imple- 
mentação de um programa de governo, sejam claras, precisas e coerentes com os seus custos e, por outro lado, compatível com a capacidade de financiamento (arrecadação).

Para uma melhor visualização, podem-se observar na Tabela 3 os índices incorridos na série de exercícios a que os dados se referem.

Tabela 3: Índice Médio de Utilização de

Créditos Adicionais - IUCA e IUCA1 - 89/93 e 95/97

\begin{tabular}{ccccc}
\hline Anos & IUCA & $\begin{array}{c}\text { Média IUCA dos } \\
\text { Períodos Analisados }\end{array}$ & IUCA1 & $\begin{array}{c}\text { Média IUCA1 dos } \\
\text { Períodos Analisados }\end{array}$ \\
\hline 1989 & 0,82 & - & 2,86 & - \\
1990 & 0,87 & - & 4,36 & - \\
1991 & 0,42 & - & 0,56 & - \\
1992 & 0,75 & - & 2,32 & - \\
1993 & 0,81 & 0,73 & 2,66 & 2,55 \\
1995 & 0,27 & - & 0,21 & - \\
1996 & 0,30 & - & 0,28 & - \\
1997 & 0,28 & 0,28 & 0,24 & 0,24 \\
\hline
\end{tabular}

Fonte: Dados da pesquisa, elaborados com base nos balanços municipais disponíveis no TCE.

Para uma melhor ilustração, esses dados podem ser observados no Gráfico 7. A linha que corta o eixo vertical em 0 (zero) representa a eficiência máxima no planejamento, avaliado sob a ótica da utilização de créditos adicionais, pois revela o menor grau de necessidade da ocorrência de ajustes no orçamento durante a sua execução.

Gráfico 7: Índice Médio de Utilização de

Créditos Adicionais - IUCA e IUCA1 - 89/93 e 95/97

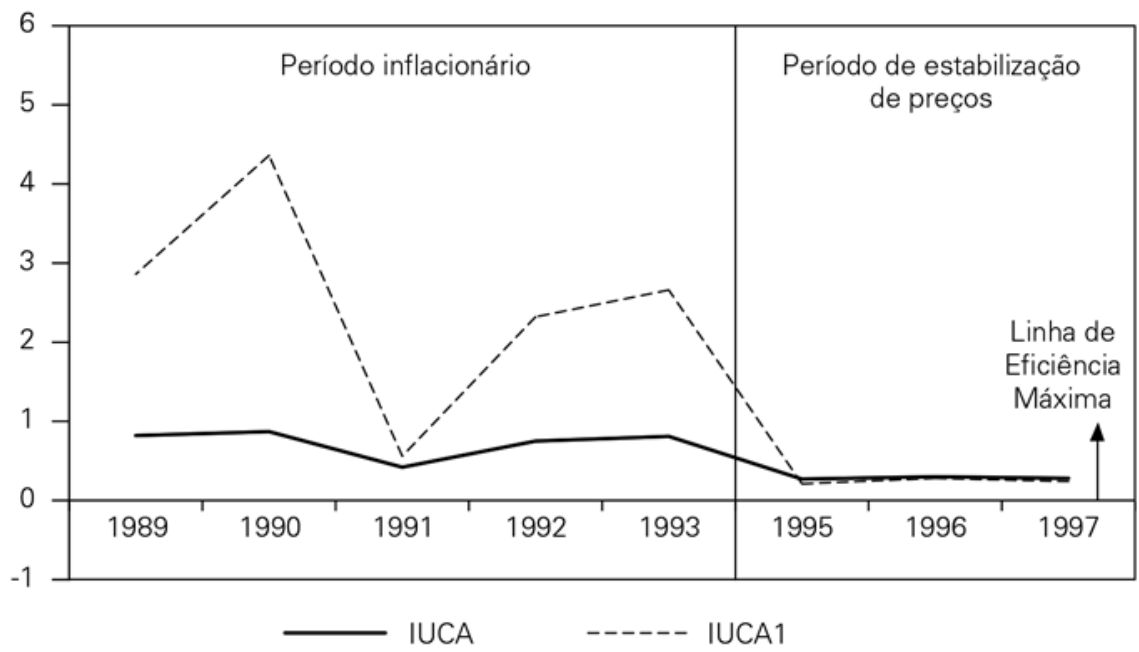

Fonte: Tabela 2 
Nota-se perfeitamente, na Tabela 3 e Gráfico 7, que, no período inflacionário, tanto o IUCA como o IUCA1 apresentaram-se em níveis bastante altos, o que revela uma grande utilização de créditos adicionais para ajustar os orçamentos dos municípios pesquisados. Essas discrepância em relação ao parâmetro que indica a eficiência máxima na técnica orçamentária e avaliada por intermédio do IUCA indica, por outro lado, o grau de discrepância da própria função planejamento, avaliada em relação à sua execução.

O IUCA médio regional, no período inflacionário, 1989 a 1993, foi de 0,73, com um desvio em relação ao padrão de eficiência máxima de 0,87 em 1990. Excluindo-se o ano de 1991, em que a média regional do IUCA foi de 0,42, muito diferente, portanto, dos outros quatro exercícios, tem-se uma média para o período de 0,81 , com um desvio em relação ao padrão de eficiência máxima também de 0,87.

Esse índice, IUCA, como já foi mencionado, refere-se a um orçamento ajustado, ou seja, é apurado em relação à despesa efetivamente realizada (empenhada) em cada ano. Bem diferente, no entanto, apresenta-se o IUCA1, que é derivado da relação com a fixação da despesa, ou seja, do planejamento inicialmente feito, sem considerar as correções nas dotações acontecidas no curso da implementação dos planos e programas através da execução orçamentária.

Aqui esse índice mostra um grau de discrepância ainda maior, atingindo uma média no período inflacionário de 2,55 , com um desvio em relação ao padrão de eficiência máxima de 4,36 (Tabela 3). Como o ano de 1991 revelou-se atípico, mostrando mais eficiência com relação ao planejamento avaliado pela técnica orçamentária, se comparado com os demais exercícios do período, no momento em que o IUCA1 é desconsiderado, sua média eleva-se para 3,05 no período, mantendo-se, é claro, o desvio em relação ao padrão máximo de eficiência, em 4,36.

Observando-se os anos que compõem o período de estabilização de preços, verifica-se também que houve discrepâncias em relação ao parâmetro de eficiência máxima do planejamento e da técnica orçamentária, que, como já se disse, é zero, com relação ao IUCA e IUCA1.

Verifica-se ainda, com base na Tabela 3, que a média regional do IUCA no período de estabilização de preços ficou em 0,28 , com um desvio em relação ao padrão de eficiência máxima de 0,30. Quanto ao IUCA1, a média regional atingiu o índice de 0,24, com um desvio em relação ao padrão de eficiência máxima de 0,28 . É bom lembrar que, nesse período, os orçamentos apresentaram-se superestimados, com índices de realizações de receitas e despesas sempre menores do que o parâmetro 1 (um), revelando a inexistência de excesso de arrecadação.

Esse fato justifica um comportamento inverso entre o IUCA e IUCA1 em relação ao período inflacionário, em nível de valores nominais. Enquanto no período inflacionário o IUCA1 sempre se revelou maior que o IUCA, no período de estabilização ocorreu o contrário. Isso aconteceu exatamente em virtude de que, no último período, os orçamentos apresentaram-se superestimados, fazendo com que as execuções se apresentassem sempre menores que o fixado para a despesa $(D F t)$ e esses dados são determinantes destes índices, já que o mesmo é originado da relação 
créditos adicionais/despesa (DFt ou DEt). Em outras palavras, nesse período, DFt sempre foi maior que DEt.

Salienta-se que, para fins de uma melhor avaliação da eficiência das técnicas orçamentárias e, em decorrência do planejamento, o IUCA1 é mais indicado já que revela sempre as discrepâncias entre o planejamento inicial e a efetiva implementação, não considerando os ajustes acontecidos durante a execução orçamentária, pois sua origem é da relação créditos adicionais/despesa fixada (CA/DFt). Isso significa dizer também que, para o período de estabilização de preços, os créditos adicionais referem-se a ajustes orçamentários decorrentes de deficiência de dotações, ou até de ausência dessas, ou de projetos e/ou atividades, mas não para a utilização de excesso de arrecadação. É nessa ótica que deve ser feita qualquer avaliação da eficiência no planejamento e das técnicas orçamentárias nesse período.

Em síntese, as análises das execuções orçamentárias através do Índice de Utilização de Créditos Adicionais permitem salientar as seguintes características: a) quando o orçamento, que deve mostrar fielmente os planos, os programas, os objetivos e metas, enfim, o próprio planejamento, apresenta um IUCA1 igual a zero, ou que fica muito próximo a esse parâmetro, evidencia coerência com o planejamento e o orçamento praticados; b) quando a execução orçamentária apresentar um IUCA1 com discrepâncias em relação ao parâmetro zero, revela que necessitou de ajustes durante a sua execução e que o nível de créditos adicionais apresentado corresponde exatamente ao nível dos ajustamentos ocorridos no próprio planejamento, já que o orçamento deve ser o reflexo do planejamento; c) quanto mais elevada é a relação excesso de arrecadação/créditos adicionais, maior se revela a discrepância entre a receita estimada e a receita arrecadada, o que também mostra, incoerência entre o planejamento e o orçamento. Esse dado mostra, igualmente, que o orçamento foi subestimado, fato que permitiu o excedente na arrecadação; d) quando o IUCA1 é elevado, porém com um baixo nível de excesso de arrecadação, evidencia que houve elevado nível de ajuste orçamentário em conseqüência do planejamento, com a transposição de créditos já existentes no orçamento inicial. Revela também que os orçamentos foram superestimados e/ou incoerência entre o que se planejou e aquilo que se executou efetivamente.

\subsection{Padronização municipal de acordo com os índices de despesa, receita e de créditos adicionais}

No confronto entre o Índice de Acerto na Estimação da Receita — IAER - e o Índice de Acerto na Fixação da Despesa - IAFD, pode-se apurar o grau de endividamento dos organismos municipais em cada exercício. Para tanto, é preciso levar em consideração que a contabilidade pública estabelece a adoção do Regime Contábil Misto para as receitas e despesas públicas, segundo o que expressa o art. 35 da lei federal $n^{\circ} 4320 / 64$, ao definir que "pertencem ao exercício financeiro as receitas nele arrecadadas e as despesas nele legalmente empenhadas". Significa dizer que são registradas como receitas do exercício aquele montante efetivamente arrecadado durante o ano. 
Quanto à receita, o regime de caixa e a efetiva arrecadação permitem concluir que somente o efetivo ingresso pode ser considerado pertencente ao exercício, permanecendo como crédito que será inscrito em dívida ativa desse mesmo exercício, aqueles valores lançados e com a identificação do devedor, no valor exato que a lei autoriza.

Quanto à despesa, o regime de competência obriga ao reconhecimento, no exercício, de todas as despesas legalmente empenhadas, as quais devem ser devidamente ordenadas por pessoa legalmente investida na autoridade de empenhar, seja por ocupação do cargo próprio, seja por delegação de competência. Devem ter sido previamente empenhadas e originadas de leis, contratos, acordos, convênios etc. e ter sido autorizadas pela lei orçamentária ou pelos ajustes originados por créditos adicionais.

Comparando, então, o regime de caixa para a receita e o de competência para a despesa, o que se percebe é que a Gestão Orçamentária pode influenciar apenas sobre a despesa, que deve ter sua realização autorizada, ao passo que, no caso da receita, seu ingresso vai obedecer ao comportamento efetivo de mercado, alheio à vontade e decisão do administrador. Isso revela que, no momento em que são estabelecidos orçamentos superestimados, a lei cria a possibilidade de se gastar na esfera pública além da real capacidade de ingresso nos cofres do Erário, gerando um déficit orçamentário pelo desequilíbrio entre os ingressos efetivos e os compromissos assumidos, gerando, também, um déficit financeiro.

A Tabela 4 mostra o comportamento havido entre os 67 municípios estudados. Quando os orçamentos são superestimados, como tem acontecido no período de estabilização de preços, ou seja, 1995, 1996 e 1997, há uma autorização legislativa para que os executivos realizem as despesas até o montante dos créditos orçamentários. No entanto, tal autorização de gastos públicos está fora da realidade econômico-financeira em razão da superavaliação.

Tabela 4: Comportamento da Execução Orçamentária Municipal e Déficit ou Superávit Anual em Relação ao Orçamento Inicial - 1989/1993 e 1995/1997

\begin{tabular}{lcccccccc}
\hline \multicolumn{1}{c}{ Indicador } & 1989 & 1990 & 1991 & 1992 & 1993 & 1995 & 1996 & 1997 \\
\hline Total de municípios & 67 & 67 & 67 & 67 & 67 & 67 & 67 & 67 \\
Municípios com superávit & 55 & 46 & 40 & 29 & 51 & 15 & 3 & 33 \\
Percentual (\%) & 82,1 & 68,7 & 59,7 & 43,3 & 71,1 & 22,4 & 4,5 & 49,3 \\
Municípios com déficit & 12 & 21 & 27 & 38 & 16 & 52 & 64 & 34 \\
Percentual (\%) & 17,9 & 31,3 & 40,3 & 56,7 & 23,9 & 77,6 & 95,5 & 50,7 \\
Superávit médio (\%) & 38,9 & 14,7 & 4,2 & $(6,9)$ & 25,7 & $(3,28)$ & $(8,0)$ & 1,3 \\
Maior superávit (\%) & 29,5 & 384,1 & 87,5 & 50,0 & 87,4 & 4,5 & 3,7 & 28,5 \\
Maior déficit (\%) & 51,9 & 5,1 & 13,5 & 19,0 & 35,8 & 15,0 & 34,2 & 9,9 \\
\hline
\end{tabular}

Fonte: Dados da pesquisa, elaborados com base nos balanços municipais disponíveis no TCE. 
Há, nesse caso, uma grande responsabilidade social por parte dos legisladores quando da apreciação e aprovação da lei orçamentária de cada exercício. A lei de orçamento é uma lei de importância máxima para a comunidade municipal, pois nela estão propostos todos os programas a serem desenvolvidos em prol dos cidadãos, através dos projetos e das atividades elencados no orçamento-programa. As receitas são apenas estimativas ali elencadas, mas os créditos orçamentários distribuídos nos diversos elementos de despesas - elencados segundo a classificação determinada pela lei federal $\mathrm{n}^{\circ} 4.320 / 64$, como pessoal, material de consumo, serviços de terceiros e encargos, obras e instalações, equipamentos e material permanente etc. - , não só revelam o custeio dessas atividades e projetos, como correspondem, acima de tudo e antes de quaisquer outras considerações, a autorização legislativa para a assunção de compromissos para a municipalidade.

Por outro lado, como a demanda por serviços públicos tem se revelado maior do que a capacidade de atendimento, a administração por fluxo de caixa nesses exercícios tem permitido um alto grau de endividamento em muitos municípios, já que houve uma autorização orçamentária além da realidade. No entanto, nos exercícios de 1992 e 1996, as conseqüências com relação ao nível de endividamento foram mais acentuadas, exatamente por ser ano eleitoral, havendo pleito para os cargos eletivos de prefeito, vice-prefeito e vereadores na esfera municipal.

Constata-se que, na ânsia de oferecer mais e melhores serviços públicos, obras e equipamentos comunitários, no exercício em que o Executivo tenta obter uma melhor aprovação popular, buscando um resultado desejado nas urnas, tanto no exercício de 1992 como no de 1996, que houve a realização de despesas, que já estavam autorizadas desde o final de 1991 e 1995, sem a correspondente resposta da arrecadação.

No ano de 1996, esse fato ficou bem comprovado em razão dos dados levantados, pois, dos 67 municípios pesquisados, apenas três não gastaram mais do que arrecadaram, o que corresponde a 4,48\% do universo. Quanto aos outros 95,52\%, esses abandonaram a gestão do fluxo de caixa, usando a autorização para a realização de despesas em níveis superestimados que o orçamento consignava. O nível de endividamento médio regional foi de $8 \%$ acima da efetiva arrecadação, comprovado pelo índice de déficit ou superávit orçamentário, que foi, nesse ano, de 0,08. Tal índice é proveniente da diferença entre o IAER e o IAFD. Observando os dados da Tabela 4, verifica-se que, no período de estabilização de preços, o fator endividamento médio esteve muito presente, $3,28 \%$ em 1995 , contra $1,35 \%$ de superávit em 1997, porém com 8\% no ano de 1996.

Os dados têm revelado que, havendo orçamentos subestimados ou superestimados, como demonstra a série de anos, houve, por parte do Executivo, a necessidade de uma verdadeira administração do fluxo de caixa para fazer com que o nível de realização das despesas acompanhasse os ingressos efetivos de receitas. Notase também que isso nem sempre ocorreu, havendo alguns desequilíbrios facilmente visualizáveis. Contudo, os desequilíbrios verificados nos exercícios pertencentes ao período de estabilização de preços, com alta delegação legislativa para a realização de despesa muito além da realidade local, foram bem mais acentuados, 
chegando a uma média deficitária de $8 \%$ no exercício de 1996 e de 3,28\% no exercício de 1995. Esses dois resultados forçaram as novas administrações municipais que assumiram suas gestões no ano de 1997 a gerir o fluxo de caixa do exercício de maneira bem mais racional que nos exercícios anteriores, exatamente para poder gerar sobras financeiras para saldar os compromissos assumidos, além da capacidade de pagamento. Isso está comprovado pelo superávit médio de 1,35\% ocorrido em 1997.

\section{CONCLUSÕES E IMPLICAÇÕES FINAIS}

Este artigo teve como escopo avaliar o orçamento e a eficiência do planejamento municipal no período de 1989 a 1997. Para atingir esse objetivo, foram construídos índices sobre as variáveis orçamentárias da receita, da despesa e dos créditos adicionais.

Os resultados principais sobre o acerto na fixação das despesas orçamentárias indicam, em geral, que as variáveis inflação e estabilização de preços não são determinantes para o planejamento e conseqüente elaboração e execução dos orçamentos, funções governamentais e executivas que se concretizam de forma plenamente inter-relacionadas.

Constatou-se que, no período inflacionário, o acerto médio na fixação das despesas orçamentárias, se comparado com o índice representativo de eficiência máxima, normalmente apresentou-se acima de um e em altos níveis, revelando a prática generalizada de subavaliação das dotações, para custear os bens e serviços públicos elencados nos projetos e atividades listados nas peças orçamentárias, representativos do planejamento concebido; já no período de estabilização de preços, esse índice caracteriza-se por uma prática de superestimação desses custos.

Quanto ao acerto médio na estimação da receita, tanto no período considerado inflacionário como no de estabilização de preços, os problemas assemelham-se ao acerto médio das despesas fixadas. Tal comportamento já era esperado, visto que tais índices são altamente relacionados em função do princípio do equilíbrio orçamentário. Isso significa dizer também que a verdadeira capacidade de arrecadação dos cofres municipais não foi expressa nos documentos legais representativos do planejamento, que são os orçamentos. Neles, não ficaram expressos os montantes de recursos, fonte financiadora dos serviços, obras e equipamentos públicos objetivados nos projetos e atividades consignados nos orçamentos anuais, em qualquer dos períodos estudados. Novamente, portanto, comprovaram as duas diferentes práticas orçamentárias nos municípios pesquisados, ou seja, a primeira, de subavaliação orçamentária no período inflacionário, e a segunda, de superavaliação orçamentária no período de estabilização dos preços.

Cabe salientar que os desvios dos índices de acerto na fixação das despesas e na estimativa da receita, sempre em uma linha superior em relação ao índice de eficiência máxima, no período inflacionário, acarretaram um alto índice de utilização de créditos adicionais, exatamente para adicionar autorização de despesas 
inicialmente fixadas, para fazer frente aos acréscimos dos custos dos bens e serviços, utilizando o excedente arrecadado como fonte para suportar os custos suplementares. Essa prática está prevista na legislação que estabelece normas gerais de direito financeiro, porém comprova um alto grau de necessidade de ajuste nos orçamentos propostos e aprovados pelo poder Legislativo de cada município, revelando, por um lado, desajuste no planejamento e, por outro, que ele foi concebido de forma não factível ou realista.

Sob o particular, os desacertos na fixação da despesa e na estimação da receita também podem ser explicados através das influências políticas, já que o gestor do orçamento, que nos municípios pequenos é sempre de responsabilidade do chefe do poder Executivo, e que normalmente são mais habilidosos no trato de relações humanas e institucionais e pouco conhecem das técnicas orçamentárias, estabelecendo seus planos de forma divorciada da realidade das cifras, tanto dos custos dos serviços e bens públicos como das fontes de financiamento desses. Por outro lado, os planos econômicos - regulamentados por força de decretos-lei até 4 de outubro de 1988 e por medidas provisórias a partir desta data - muito colaboraram para os desajustes dos planos e programas dos governos municipais e, conseqüentemente, de seus orçamentos.

Os resultados das análises indicam, igualmente, carência no planejamento em quase todos os municípios que fizeram parte da pesquisa.

O orçamento-programa, ao qual devem se submeter todos os municípios e que deve revelar um plano de trabalho do governo, nele especificando-se as proposições concretas que esse governo pretende realizar durante um determinado exercício, expresso em termos físicos e financeiros, não ficou evidenciado pelas análises dos dois períodos em exame. Isso, de fato, não tem ocorrido nos organismos municipais que fizeram parte da pesquisa. Os orçamentos municipais são concebidos, em nível de estimação de suas receitas e fixação das despesas, de forma que não se coadunam com a real capacidade de arrecadação dos cofres públicos.

Esse fato tem ocorrido, em parte, pela cultura inflacionária que se instalou na sociedade brasileira, influenciando, de modo geral, nas decisões sobre as previsões orçamentárias pelas incertezas do comportamento dos níveis de preços da economia, com reflexos diretos sobre os ingressos públicos e sobre os custos dos bens e serviços prestados pela administração pública.

Os dados revelaram a ausência de ligação entre o planejamento e os orçamentos, contrariando a legislação, bem como todos os princípios orçamentários, além de o documento técnico, que é a peça orçamentária, não representar o plano anual de governo. Assim, os projetos e atividades alocados nos orçamentos anuais não tiveram seus custos reais que permitissem e propiciassem as suas realizações, uma vez que os orçamentos sempre se apresentaram subestimados ou superestimados, de acordo com o período inflacionário e o período de estabilização de preços, respectivamente.

Ficou evidenciado que, no período inflacionário, em conseqüência da subestimação das receitas, sempre ocorreram excessos nas arrecadações, de forma que houvesse a necessitando de freqüentes autorizações legislativas para a abertura de 
créditos adicionais ao orçamento inicial, para utilização do excedente orçamentário da receita e para aumento dos créditos orçamentários, com o fim de cobrir os aumentos dos custos dos bens, serviços e equipamentos públicos. Assim, o ordenador das despesas municipais atuava no gerenciamento de um verdadeiro fluxo de caixa, mas com o aval constante do Legislativo para cada nova autorização para a abertura de crédito adicional. Esse período ficou bem caracterizado como superavitário, com exceção apenas do ano de 1992, quando ocorreu o pleito eleitoral na esfera municipal para os cargos de prefeito, vice-prefeito e vereadores.

Fato parecido a esse apresenta o ano de 1996, quando também ocorreu o segundo pleito eleitoral na esfera municipal, ocasião em que se registrou o maior índice de déficit orçamentário entre os dois períodos e nos municípios compreendidos pela pesquisa.

Novamente, no período de estabilização de preços, com orçamentos superestimados, foi permitido, por parte do poder Legislativo, ao ordenador da despesa orçamentária a gestão pura e simples de um fluxo de caixa. Porém, nesse período, com ampla liberdade para assumir compromissos, em vista dos montantes fixados para a despesa estarem em níveis superiores à capacidade de ingressos a título de receita orçamentária. Nesse período, a vigilância do poder Legislativo ficou alheia, sem poder de ação, pois as autorizações já estavam consignadas na lei orçamentária de forma integral e, pior, com excesso de autorização. Como conseqüência natural disso, constata-se uma realização de despesa bem maior que os ingressos orçamentários a título de receitas, caracterizando o período de estabilização de preços como deficitário.

O exposto sugere a conclusão de que os legisladores, principalmente no período de estabilização de preços, não foram eficazes no exercício de suas funções, no tocante à apreciação, discussão e aprovação das leis orçamentárias dos municípios.

\section{REFERÊNCIAS BIBLIOGRÁFICAS}

DALLA VECCHIA, Eloi (1999) Orçamento Municipal: o caso dos Municípios do Planalto Médio de Estado do Rio Grande do Sul 1989-1997. Florianópolis, CPGA/Universidade Federal de Santa Catarina, 1999. (Dissertação de Mestrado).

MACHADO, Jr., J. Teixeira e REIS, Heraldo da Costa. (1999) A lei 4320 Comentada, Rio de Janeiro: Instituto Brasileiro de Administração Municipal $29^{a}$ ed revisada e atual. 